\title{
An Empirical Study on the PNP Maritime Group Attrition System
}

\author{
Eugene V. Juaneza
}

\begin{abstract}
In the light of the limited literature and studies on the Philippine National Police (PNP) Military attrition system, this study was conducted in a pioneering spirit. To determine how PNP Maritime Group view the PNP attrition system and problems in its implementation, a total of 92 randomly selected PNP Maritime Group personnel were requested to answer a researcher-made validated questionnaire. Respondents were likewise asked for their recommendations to improve the system. The study revealed that there are no significant differences among the perceptions $(\mathrm{P}=0.536687)$ of the respondents on the attrition system, problems encountered $(\mathrm{P}=0.187221)$ in its implementation and recommendations $(\mathrm{P}=0.010042)$. Results of study provide a compelling case for policy-makers to create feedback mechanisms like seminars, focus group discussions and conferences pertaining to PNP Maritime Group attrition system in order to communicate its real purpose. Further research may expand the participants to include higher posts in order to scale the perception and problems encountered during the implementation of the system.
\end{abstract}

Keywords:

Philippine National Police, Attrition System, R.A. 8551, Police Personnel, PNP Maritime Group

Suggested Citation: Juaneza, E. V. (2021). An Empirical Study on the PNP Maritime Group Attrition System. International Journal of Academe and Industry Research, Volume 2, Issue 2, pp. 25- 44.

About the author:

MS degree holder. P/Major, Philippine National Police. 


\section{Introduction}

The abolition of the Philippine Constabulary and Integrated National Police and the subsequent transformation into a single organization in 1991 brought about various personnel and organizational concerns for the PNP. One of the problems is the lack of credibility and operational effectiveness due to the presence of unfit and unproductive personnel. In 1998, the Republic Act 8551 PNP Reform and Reorganization was passed into law and consequently mandated the PNP to establish and submit to the National Police Commission a system of attrition for uniformed personnel.

In the context of the PNP, attrition refers to the retirement or separation from the police service of PNP Uniformed Personnel pursuant to any of the means mentioned in Sections 24 to 29 of RA 8551 and other means as provided in the circular. This is different from voluntary departure where personnel make a decision to depart from an organization due to one or several reasons. Voluntary departure does not include removal due to dismissal or conduct dismissal from service, therefore it is the exact opposite of attrition. Attrition system is a scheme or set of mechanisms that spell out disqualifications, ground and procedures for the dismissal of personnel as provided for in Section 24 to 30 of RA 8551.

The implementation of the attrition system is considered controversial because of its impact on the professional and personal lives of affected personnel. There is a linkage between its attrition system and separation and retirement system. Current statistics reported that a portion of General Annual Appropriations (GAA) is allotted for personnel services, which includes the monthly salaries and allowances of uniformed police personnel. From this allocation, a certain percentage is also set aside to meet fund requirements for separation and retirement benefits. The main areas considered in the attrition process include performance evaluations, physical fitness, career development, and the educational requirements. Separation from the service through attrition is done when personnel have attained the maximum tenure in position, non-assignment, and demotion in position, non-promotion or by any other means as specified by the law. A poor performance evaluation based on periodic ratings may prompt the grievance committee to review the attrition of the personnel. It may also be imposed on personnel who may be deemed as no longer physically and/ or mentally fit. 
This study was conducted to assess the perception of the three groups of personnel, Police Commissioned Officers, Police Non-Commissioned Officers, and Non-Uniformed Personnel in the implementation of the attrition system. Moreover, the scope of analysis extended to showing the relationships between and among perceptions, problems encountered and recommendations. Specifically, it assessed the insights of the respondents on the attrition system under R.A. 8551 in terms of attrition by attainment of maximum tenure in position, attrition by relief, attrition by demotion in position, attrition by nonpromotion and attrition by other means and the problems encountered in the implementation of the attrition system.

\section{Literature review}

\subsection{Employee Attrition and Turnover}

Employee retention has piqued the interest of scholars and businesses in a variety of industries during the last few decades. To remain competitive in the fast-expanding global economy and keep up with technological changes, businesses and academic institutions must have a workforce with strong institutional knowledge (Benko and Weisberg, 2007; Becker, 2007; The Future of Work 2020, 2007). Whenever an employee leaves the organization and does not get replaced for a longer time, it is regarded as employee attrition (Burbank Planning, 2021; Robinson, 2021). Employee attrition is the cycle of employment. When employees leave the company, it can be voluntary resignation from the job or even illness or death (Burban Planning, 2021). Instead of employing new employees, employers frequently cut positions, restructure departments, or impose a hiring freeze. Employee attrition can occur for a variety of reasons, including cost-cutting and organizational restructuring (Robinson, 2021; Tech Funnel, 2020). Employees are an organization's most valuable resource. In any case, if they left their employment unexpectedly, it could result in a significant financial loss for any company. Because new hiring costs money and time, as well as requiring newly employed personnel to put in some effort to make the company productive (Harsha, et. al, 2020).

Employee attrition is the steady but deliberate reduction of a company's or business organization's workforce which can lead to leadership gap if senior executives leave, or it can 
undermine workplace diversity if employees who belong to minority groups leave. It can be caused by a lack of trust in the company's leadership and market value, as well as a hostile work environment and a lack of professional development (Tech Funnel, 2020) which can lead to voluntary attrition. The voluntary attrition is also known as voluntary resignation wherein employee leaves the organization at their own will. Some employees choose to leave the organization because of reasons such as burnout, stress, lack of applications, job and skills mismatch, limited career growth and better offer from other companies. Job satisfaction is strongly and inversely related to an employee's intention to leave a business (MacIntosh and Doherty, 2010; Silverthorne, 2004). Employees who are satisfied are less likely to look for a new job with a new company (Medina, 2012). According to Robinson (2021), "Life events are often the catalyst for career changes". Some younger people in the workforce have an inclination for "job shopping" and experiment with their career aspirations.

Another form of attrition is the internal attrition where a person is required to leave their allocated team or department in order to join another (Burban Planning, 2021). It happens when people leave one department to work in another department within the company (Tech Funnel, 2020). Most of the time, this is a beneficial move, and a skilled individual stays with the company. This usually occurs as a result of a well-organized HR process and corporate rules. However, if there are numerous similar shifts occurring even within the organization, it must be concerning. It is preferable to find out why this is happening and take corrective measures, as it generates a negative impression of the present process and causes people to leave (Reddy, 2021). On the other hand, involuntary attrition is when the employee has to leave the job or gets terminated due to their ethical misconduct or incompetence in the discharge of their job functions (Burban Planning, 2021). This form of attrition is dependent on employers or organizations to initiate the attrition process. It may also be due to structural changes through acquisition or a merger (Tech Funnel, 2020). Moreover, demographic attrition is a type of attrition that is exclusive to a single group. People with disabilities, ethnic minorities, veterans and senior professionals, and even women could be among them. When a certain demographic group begins to leave the organization in big numbers, the company's policies should be reviewed (Tech Funnel, 2020). 
Attrition and turnover have similar causes, but they are not the same. Organizations have always been concerned about employee turnover (Zhang, 2016) which could damage both the organization and the personnel (Jeen, 2014). Employee turnover rates varies in different industries. The report by LinkedIn Corporation (2018) reveals that in 2017, Tech companies (software) have the highest turnover rate of $13.2 \%$, followed by Retail at $13.0 \%$, while media/entertainment industry garnered $11.4 \%$, professional services $(11.4 \%)$, and government/education/non-profit $(11.2 \%)$. For the past few years, these sectors have consistently seen the highest turnover rates. If organizations let this trend continue, voluntary turnover will hit $35 \%$ by 2023 , placing companies in continuous and enormous risk (Work Institute, 2019).

Turnover can be induced by the same factors that lead to attrition, although it is usually seen as a negative and a burden for employers (Dik, 2018). The two types of turnover are voluntary and involuntary. The voluntary turnover refers to an employee's decision to leave the workplace (Dik, 2018; Zhang, 2016). This is when the employees of an organization decide to quit the organization. It might be because they got a better offer elsewhere or a lack of opportunities for personal development and growth in the company. Other factors that might cause a voluntary turnover are a poor payment, hostile or unconducive work environment and the feeling of under-appreciation (Tech Funnel, 2020). Meanwhile, involuntary turnover occurs when an employee is terminated or fired (with the intent to be replaced) for a variety of reasons, including poor performance, behavioral and ethical issues, and so on (Dik, 2018). This is when the employees of an organization are forced to leave the organization. This happens when the employers have to fire or terminate an employee and start to look for ways to replace them (Tech Funnel, 2020).

\subsection{The PNP and its Attrition}

Over the course of employment, police officers regularly put themselves in danger. Serving and safeguarding the public, dealing with social disturbance, and even coping with man-made and natural calamities are all part of the minutiae of the professional lives (Safety Team, 2021). Law enforcement organizations are entrusted with a wide range of responsibilities, all of which necessitate a high level of integrity within police agencies. If this does not work successfully, law enforcement officers may be tempted to act illegally and 
outside the scope of their authority (O’Neill, 2004 as cited in UNODC, 2011). Hence, policymakers around the globe created systems that have the end-goal of improving and maintaining satisfactory standards of conduct. The human operations department of Norfolk and Suffolk police forces in Great Britain implements a policy to aid the police staff, manager and their representatives to deal with disciplinary situations in the workplace, "to ensure that every disciplinary matter will be dealt with fairly and sensitively and that everyone understands the standards of conduct the forces expect of their staff" (Norfolk HR Operations, 2020, p. 1).

In general, police officers can leave the force in four ways: voluntary resignation, dismissal for misconduct or capability, retirement, and early retirement due to bad health (Crawford, et al., 2017). Other than compensation, there are a number of factors that influence whether an officer chooses to stay with or leave an agency (Shults, 2019). Police officers exit rates, and reasons for leaving, vary among police forces (Crawford, et al., 2017 ) and their mode of departure (voluntary or involuntary) also differ across the globe. For instance, according to Knowles (2020), there will be a crisis if the voluntary departure of police officers continues in the United Kingdom. Frontline police have repeatedly spoken out about increasing violence. Leaders of the police forces attribute such early voluntary departure and resignations to increased exposure and scrutiny faced on social media, low wages and the toxic trio of violence. Experts say that losing so many experienced officers while trying to hire 20,000 new recruits - a target set by the Government - will be a "tragedy". Talented officers will be expected to take on more complex investigations as well as helping to train the newbies (Knowles, 2020). According to Ken Marsh of the UK Metropolitan Police Federation, "many are resigning due to the challenges of the job, because of what we are being asked to perform, because of the fact our employer can work us for 20 hours straight and then tell us to be back in four hours" (Marsh, as cited by Knowles, 2020).

Police officers must be given clear guidelines in order to be more responsible and accountable for actions and wrongdoings. They must also be well-prepared and equipped in order to do duties professionally, and they must be ensured of safe working environment. Police actions and operations must be monitored and evaluated, and line managers must supervise their employees (The United Nations Office on Drugs and Crime, 2011). 
Accordingly, the elements an effective police accountability system include legislation (in line with international human rights law) specifying the functions and powers of the police, practical instructions based on the legislation that reflect both the spirit and the letter of the law, opportunities for the public to voice concerns, adequate police training, both basic and ongoing, equipment that is adequate for prescribed police functions, proper reporting procedures and facilities, adequate supervision that supports officers in carrying out duties professionally and reporting these correctly, a working culture that promotes transparency and evaluation, monitoring of police actions and operations by both police leadership and external organs, complaints procedures, both for making complaints to the police directly and to independent bodies, and fair and effective procedures and policies on how to deal with misconduct, including both disciplinary and criminal codes, adequate investigative capacity, procedures for punishment and appeal procedures (UNODC, 2011, pp. 5-6).

The PNP personnel are evaluated through a standardized system. The Performance Governance System (PGS) is based on the performance management system which utilizes the "balanced scorecard" technology, the organization's roadmap for a long-term and lasting reform in the PNP. Through the PGS, the organization gets closer to attaining its vision through the efficient implementation of its strategies which lead to results. Instead of merely measuring and monitoring the organizational output, the PGS also measures the impact of the programs, projects, and activities to its employees, customers, stakeholders, the Philippine government, and the country. Thus, to accomplish this vision, the PNP-Maritime Group applied the transformation program to its personnel, one of which is the attrition system. Attrition system is under the dimension of Learning and Growth of the PGS.

For the purpose of determining compliance with the requirements on physical and mental health, as well as the non-use of prohibited drugs, the PNP by itself or through a NAPOLCOM accredited government hospital conducts regular psychiatric, psychological drug and physical tests randomly and without notice. After the lapse of the time period for the satisfaction of a specific requirement, current members of the PNP who fail to satisfy any of the requirements are separated from the service if they are below fifty (50) years of age and have served in government for less than twenty (20) years or retired if they are from the age of fifty (50) and above and have served the government for at least twenty (20) years 
without prejudice in either case to the payment of benefits they may be entitled to under existing laws.

\section{Methodology}

\subsection{Research Design and Instrument}

In order to establish the existence of relationship of the independent variable (internal factors like age, gender, years of tenure) with the dependent variable, (perception on PNP attrition system), the researcher employed descriptive and correlational research design. Descriptive research is the investigation which describes and interprets what if while correlational study is a descriptive study designed to determine which different variables are related to each other in the population of interest. The main tool used in the data gathering was researcher-made validated survey questionnaire with 39 items in a Likert-style format.

\subsection{Population and Sample}

In determining the sample size, the study used random sampling through numbers ranging from 70 to 2,055. The total number of the PNP Maritime Personnel is 2,055. A total of 92 random numbers were drawn from the list. To test the validity and reliability of the 92 sample size, the Philippine Social Science Council Survey (PSSCS) formula was used to determine the desired number of respondents with $95 \%$ confidence level and $5 \%$ margin of error. The computation of sample size using the formula yielded 70. Since the prospective sample size of 92 exceeds 70, the actual number of respondents for this study is more than enough to represent the total number of personnel in the PNP Maritime Group.

\section{Table 1}

\section{Demographic Characteristics of the Respondents}

\begin{tabular}{lll}
\hline \multicolumn{1}{c}{ Sex } & \multicolumn{1}{c}{ Group } \\
\hline $54(58.70 \%)$ are males & $72(78.26 \%)-$ PNCO & \\
$38(41.30 \%)$ are females & $11(11.96 \%)-$ PCO & \multicolumn{1}{c}{ Age Group } \\
& $9(9.78 \%)-$ NUP & \multicolumn{1}{c}{ Position } \\
\hline \multicolumn{1}{c}{ Years of Service } & \multicolumn{1}{c}{$23.91 \%-36-40$ age group } \\
\hline $50 \%$ - 10 years & $31.52 \%$ - Police Staff Sergeant & $20.65 \%-41-45$ age group \\
$25 \%-15$ years & $20.65 \%$ - Police Senior Master Sergeant & $19.57 \%-31-35$ age group \\
$9.78 \%$ - 20 years & $13.04 \%$ - Police Corporal & $14.13 \%-26-30$ age group \\
$8.70 \%$ - less than 10 years & $7.61 \%$ - Police Chief Master Sergeant & $8.70 \%-46-50$ age group \\
$6.52 \%$ - 25 years & $5.43 \%$ - Police Master Sergeant & $7.61 \%-21-25$ age group \\
& $4.35 \%$ - Police Lieutenant & $4.35 \%-51-55$ age group \\
& $4.35 \%$ - Police Captain & 1 respondent did not indicate \\
& $4.35 \%$ - Police Executive Master Sergeant & age. \\
\hline
\end{tabular}


The respondents of the study were the personnel of Maritime Group which was formerly known as the Constabulary Off-Shore Anti-Crime Battalion or (COSAC) tasked to curb illegal activities in the maritime environment. The demographic characteristics of the respondents are illustrated in the table 1.

\subsection{Data Analysis}

All the answered survey questionnaires were manually encoded. Data from the quantitative aspect of the questionnaires were processed using MS Excel Tool Pack. A data base and encoding worksheets were created in Microsoft Excel Pro. For scale and interpretation, an approximated 4-point Likert scale was used.

The collected data from each group were analyzed using Analysis of Variance or ANOVA. It was used to examine the variation across the target population and determine the existence of differences among several population means. A linear regression analysis and path analysis were also used to examine the relationship between the perceptions of the respondents as dependent variable and demographics as independent variables.

\section{Findings and Discussion}

\section{Table 2}

\section{Perceptions on PNP attrition system}

\begin{tabular}{|c|c|c|c|}
\hline Perceptions on PNP attrition system & sd & $\mathbf{X W}$ & VI \\
\hline Attrition by attainment of maximum tenure in position & 0.18 & 2.82 & $\mathrm{P}$ \\
\hline Attrition by relief & 0.17 & 2.66 & $\mathrm{p}$ \\
\hline Attrition by demotion in position & 0.09 & 2.68 & $\mathrm{P}$ \\
\hline Attrition by non-promotion & 0.08 & 3.02 & $\mathrm{P}$ \\
\hline Attrition by other means: & 0.08 & 2.78 & $\mathrm{P}$ \\
\hline $\begin{array}{l}\text { Inefficiency based on poor performance during the last two (2) successive rating } \\
\text { periods. }\end{array}$ & 0.30 & 2.65 & $\mathrm{P}$ \\
\hline Inefficiency based on poor performance for three (3) cumulative annual ratings. & 0.22 & 2.74 & $\mathrm{P}$ \\
\hline Physical and/or mental incapacity to perform police functions and duties. & 0.01 & 2.88 & $\mathrm{P}$ \\
\hline $\begin{array}{l}\text { Failure to pass the required entrance examination twice and/or finish the required } \\
\text { career courses except for justifiable reasons. }\end{array}$ & 0.38 & 2.72 & $\mathrm{P}$ \\
\hline Refusal to take a periodic PNP Physical Fitness Test without justifiable reason. & 0.47 & 2.75 & $\mathrm{P}$ \\
\hline $\begin{array}{l}\text { Failure to take PNP Physical Fitness Test for four (4) consecutive periodic test due to } \\
\text { health reason }\end{array}$ & 0.47 & 2.82 & $\mathrm{P}$ \\
\hline $\begin{array}{l}\text { Failure to pass PNP Physical Fitness Test for two (2) consecutive periodic test or four } \\
\text { (4) cumulative periodic test }\end{array}$ & 0.22 & 2.83 & $\mathrm{P}$ \\
\hline $\begin{array}{l}\text { Non-compliance with the minimum qualification standards for the permanency of } \\
\text { original appointment }\end{array}$ & 0.46 & 2.85 & $\mathrm{P}$ \\
\hline
\end{tabular}


The respondents perceive that attrition is manifested through attainment of maximum tenure in position (2.82; Perceived), relief from service (2.66; Perceived), demotion in position (2.68; Perceived). The item attrition by non-promotion garnered the highest weighted mean of 3.02 (Perceived). The respondents also perceive that attrition is carried out because of other reasons like inefficiency based on poor performance during the last two (2) successive rating periods (2.65; Perceived), inefficiency based on poor performance for three (3) cumulative annual ratings (2.74; Perceived), physical and/ or mental incapacity to perform police functions and duties (2.88; Perceived), failure to pass the required entrance examination twice and/or finish the required career courses except for justifiable reasons (2.72; Perceived), refusal to take a periodic PNP Physical Fitness Test without justifiable reason (2.75; Perceived), failure to take PNP Physical Fitness Test for four (4) consecutive periodic test due to health reason (2.82; Perceived), failure to pass PNP Physical Fitness Test for two (2) consecutive periodic test or four (4) cumulative periodic test (2.83; Perceived), and non-compliance with the minimum qualification standards for the permanency of original appointment (2.85; Perceived).

\section{Table 3}

Problems encountered in the implementation of the attrition system

\begin{tabular}{|c|c|c|c|}
\hline Problems encountered in the implementation of attrition system & sd & $\mathbf{X W}$ & VI \\
\hline Attrition by attainment of maximum tenure in position & 0.34 & 2.83 & $\mathrm{~S}$ \\
\hline Political behavior and organizational Politics & 0.32 & 2.79 & S \\
\hline The perception that seniority prevail over merit & 0.37 & 2.87 & $\mathrm{~S}$ \\
\hline Attrition by relief & 0.38 & 2.80 & $\mathrm{~S}$ \\
\hline Lack of Managerial System or complementary HRM system & 0.27 & 2.71 & $\mathrm{~S}$ \\
\hline Personnel with criminal nor administrative cases & 0.49 & 2.90 & $\mathrm{~S}$ \\
\hline Attrition by demotion in position & 0.18 & 2.89 & $\mathrm{~S}$ \\
\hline Graft and corrupt practices of some PNP personnel & 0.26 & 3.11 & $\mathrm{~S}$ \\
\hline Favouritism in the selection of Table of Organization position & 0.26 & 2.79 & $\mathrm{~S}$ \\
\hline Discrimination in terms of commissionship in officer corps & 0.08 & 2.77 & $\mathrm{~S}$ \\
\hline Attrition by non-promotion & 0.16 & 2.78 & $\mathrm{~S}$ \\
\hline Slow and bureaucratic recruitment process & 0.24 & 2.82 & $\mathrm{~S}$ \\
\hline Failure to satisfy the minimum qualification standards & 0.23 & 2.76 & $\mathrm{~S}$ \\
\hline Failure to comply with other requirements for promotion to the next higher rank & 0.10 & 2.74 & $\mathrm{~S}$ \\
\hline Favoritism in the selection of Table of Organization position for promotion & 0.27 & 2.79 & $\mathrm{~S}$ \\
\hline Attrition by other means & 0.12 & 2.74 & $\mathrm{~S}$ \\
\hline Inconsistent Rules and Regulation & 0.13 & 2.78 & $\mathrm{~S}$ \\
\hline Excessive Rules and Regulations & 0.23 & 2.67 & $\mathrm{~S}$ \\
\hline Presence of Unnecessary Rules and Regulation & 0.13 & 2.73 & $\mathrm{~S}$ \\
\hline Inefficiency based on poor performance & 0.22 & 2.75 & $\mathrm{~S}$ \\
\hline Physical and mental incapacity & 0.20 & 2.77 & $\mathrm{~S}$ \\
\hline Personnel is incapable of performing police functions and duties & 0.10 & 2.73 & $\mathrm{~S}$ \\
\hline
\end{tabular}


The respondents consider the following as serious problems encountered in the implementation of attrition system: political behavior and organizational politics (2.79; Serious), the perception that seniority prevail over merit (2.87; Serious), lack of Managerial System or complementary HRM system (2.71; Serious), personnel with criminal nor administrative cases (2.90; Serious), graft and corrupt practices of some PNP personnel (3.11; Serious), favouritism in the selection of Table of Organization position (2.79; Serious), discrimination in terms of commissionship in officer corps (2.77; Serious), slow and bureaucratic recruitment process (2.82; Serious (S)), failure to satisfy the minimum qualification standards (2.76; Serious), failure to comply with other requirements for promotion to the next higher rank (2.74; Serious), favoritism in the selection of Table of Organization position for promotion (2.79; Serious), inconsistent rules and regulations (2.78; Serious), excessive rules and regulations (2.67; Serious), presence of unnecessary rules and regulations (2.73; Serious), inefficiency based on poor performance (2.75; Serious), physical and mental incapacity (2.77; Serious), and personnel are incapable of performing police functions and duties (2.73 Serious).

\section{Table 4}

\section{Proposed recommendations}

\begin{tabular}{|c|c|c|c|}
\hline Proposed recommendations & sd & $\mathbf{X W}$ & VI \\
\hline Establish a rational, fair and transparent placement board. & 0.25 & 3.63 & HR \\
\hline Establish promotional system using merits and fitness as the primary consideration & 0.45 & 3.55 & HR \\
\hline Ensure equal access and opportunity for professional growth & 0.41 & 3.64 & HR \\
\hline Career advancement for all eligible officers regardless of the source of commission & 0.38 & 3.64 & HR \\
\hline $\begin{array}{l}\text { Disciplinary Authority shall act immediately without delay to any protest, complain or } \\
\text { grievance arising from the implementation of the Circular }\end{array}$ & 0.37 & 3.63 & HR \\
\hline
\end{tabular}

Overall, the respondents highly recommend the following: PNP Maritime Group may establish a rational, fair and transparent placement board (3.63; Highly Recommended), establish promotional system using merits and fitness as the primary consideration (3.55; Highly Recommended), ensure equal access and opportunity for professional growth (3.64; Highly Recommended) and career advancement for all eligible officers regardless of the source of commission (3.64; Highly Recommended). It is imperative that disciplinary Authority shall act immediately without delay to any protest, complain or grievance arising from the implementation of the Circular (3.63; Highly Recommended). 


\section{Table 5}

Test of significant difference on the responses

\begin{tabular}{cccc}
\hline F & F crit & P-value & Decision \\
\hline \multirow{2}{*}{1.707405} & 3.09887 & 0.187221 & $\begin{array}{c}\text { Accept } \mathrm{H}_{01} \\
\text { Reject } \mathrm{H}_{\mathrm{a} 1}\end{array}$ \\
\hline
\end{tabular}

$\mathrm{H}_{01}$ There is no significant difference among the perceptions of the respondents from PCO, PNCO and NUP on the Attrition System under R.A. 8551.

There is no significant difference $\left(P_{\text {value }} 0.187221>\alpha\right)$ among the perceptions of the respondents from PCO, PNCO and NUP on the Attrition System under R.A. 8551 because the $P$-value is greater than the alpha $(\alpha=0.05)$ or level of significance. In terms of variance, the $F$-computed $(F=1.707405)$ is lower than the $F$-critical $\left(F_{\text {crit }}=3.09887\right)$ which further confirms that there is no significant difference among perceptions of the respondents from PCO, PNCO and NUP on the Attrition System under R.A. 8551. The null hypothesis is accepted and the alternative hypothesis is rejected.

\section{Table 6}

Test of significant difference on the problems encountered

\begin{tabular}{cccc}
\hline F & F crit & P-value & Decision \\
\hline 1.905555 & 3.09887 & 0.154759 & $\begin{array}{c}\text { Accept } \mathbf{H}_{\mathbf{0}} \\
\text { Reject } \mathbf{H}_{\mathbf{2} 2}\end{array}$ \\
\hline
\end{tabular}

$\mathbf{H}_{\mathbf{0} 2}$ There is no significant difference among the problems encountered in the implementation of R.A. 8551 as perceived by the respondents from PCO, PNCO and NUP.

There is no significant difference $\left(\mathrm{P}_{\text {value }}=0.154759>\alpha\right)$ among the problems encountered in the implementation of R.A. 8551 as perceived by the respondents from PCO, PNCO and NUP since the P-value is greater than the alpha $(\alpha=0.05)$ or level of significance. Furthermore, in terms of variance, the F-computed $(\mathrm{F}=1.905555)$ is lower than the F-critical $\left(\mathrm{F}_{\text {crit }}=3.09887\right)$ which further confirms that there is no significant difference among the problems encountered in the implementation of R.A. 8551 as perceived by the respondents. Thus, the null hypothesis is accepted and the alternative hypothesis is rejected. 


\section{Table 7}

Test of significant difference on the recommendations

\begin{tabular}{cccc}
\hline F & F crit & P-value & Decision \\
\hline 4.8502 & 3.100069 & 0.010042 & $\begin{array}{l}\text { Reject } \mathbf{H}_{03} \\
\text { Accept } \mathbf{H}_{\mathrm{a3}}\end{array}$ \\
\hline
\end{tabular}

$\mathrm{H}_{03}$ There is no significant difference among the recommendations of the respondents from PCO, PNCO and NUP.

There is a significant difference $(0.010042<\alpha)$ among the recommendations of the respondents from $\mathrm{PCO}, \mathrm{PNCO}$ and NUP on how to improve the current attrition system because the $\mathrm{P}$-value is much lower than the alpha $(\alpha=0.05)$ or level of significance. In terms of variance, the $F$-computed $(F=4.8502)$ is greater than the $F$-critical $\left(F_{\text {crit }}=3.100069\right)$ which further indicates that there is a significant difference among the recommendations of the respondents from PCO, PNCO and NUP. Thus, the null hypothesis is rejected and the alternative hypothesis is accepted.

\section{Table 8}

Test of Relationship between the Perceptions of the Respondents and the Problems Encountered

\begin{tabular}{cc}
\hline \multicolumn{1}{c}{ Regression Statistics } \\
\hline Multiple R & 0.401293 \\
R Square (Coefficient of determination) & 0.161036 \\
Adjusted R Square & 0.151714 \\
Standard Error & 0.463616 \\
Coefficients & 1.713653 \\
Standard Error & 0.262118 \\
t Stat & 6.537717 \\
$P$-value & $7.36 \mathrm{E}-05 / 0.00$ \\
\hline
\end{tabular}

$\mathbf{H}_{04}$ There is no relationship between the perceptions of the respondents on R.A. 8551 and the problems encountered in the implementation of attrition system.

There is a relationship $(7.36 \mathrm{E}-05<\alpha)$ between the problems encountered in the implementation of attrition system and the perceptions of the respondents on the said system because the $p$-value is lower than the alpha $(\alpha=0.05)$ or level of significance. This regression analysis result signifies that the problems encountered in the implementation of attrition system have affected or influenced how the respondents perceive the said system regardless of their gender, age, rank/ position and designation within the PNP Maritime Group. 
With regard to the testing of the strength of the relationship between problems encountered and perception, the coefficient of determination $(\mathrm{R}$-square $=0.161036)$ reveals that $16.10 \%$ of the changes in perception of the respondents can be explained by problems encountered in the implementation of the system, consequently, the Null hypothesis is rejected and the alternative hypothesis is accepted. The adjusted coefficient of determination (adjusted $\mathrm{R}$ square) has a value of 0.151714 , indicating that $15.17 \%$ of the observed variance on the respondents' perception can be attributed to the problems encountered, with the other $84.83 \%$ possibly caused by other factors.

In the PNP Maritime Group, the relationship between the problems encountered in implementation of attrition system and personnel perceptions on the system is very strong. The coefficient of determination values (R-square) and adjusted coefficient of determination values (Adjusted R-square) indicate the problems encountered strongly affect the perceptions of the respondents.

\section{Table 9}

Analysis of Variance for the perception of the respondents and the problems encountered

\begin{tabular}{ccccc}
\hline Source of Variation & SS & MS & F & F crit \\
\hline Regression & 3.713115 & 3.713115 & 17.27516 & $7.36 \mathrm{E}-05 / 0.00$ \\
Residual & 19.34455 & 0.214939 & & \\
Total & 23.05767 & & & \\
\hline
\end{tabular}

In terms of variation in regression, the F-computed (17.27516) is much higher than the value of F-critical (7.36E-05) which indicates that there is a significant difference between the values of perception and problems encountered.

Table 10

Test of Relationship between the Perceptions of the Respondents and the Proposed Recommendations

\begin{tabular}{cc}
\hline \multicolumn{2}{c}{ Regression Statistics } \\
\hline Multiple R & 0.326012 \\
R Square (Coefficient of determination) & 0.106284 \\
Adjusted R Square & 0.096354 \\
Standard Error & 0.550921 \\
$t$ Stat & 3.271566 \\
$P$-value & 0.001517 \\
\hline
\end{tabular}

$\mathrm{H}_{05}$ There is no relationship between the perceptions of the respondents on R.A. 8551 and their proposed recommendations. 
Since the $p$-value is much lower than the alpha $(\alpha=0.05)$ or level of significance, there is a relationship $(0.001517<\alpha)$ between the perceptions of the respondents and their recommendations. Regression statistics for hypothesis 5 convey that the perceptions of the respondents have somehow shaped/influenced their recommendations. In a nutshell, how the respondents perceive the said system regardless of their gender, age, rank/ position and designation within the PNP Maritime Group have affected their recommendations.

In the context of the testing of the strength of the relationship between perceptions and recommendations, the coefficient of determination $(\mathrm{R}$-square $=0.106284)$ reveals that $10.63 \%$ of the changes in recommendations by the respondents can be explained by perceptions in the implementation of the system. Accordingly, the Null hypothesis is rejected and the alternative hypothesis is accepted. The adjusted coefficient of determination (adjusted R square) has a value of 0.096354 , indicating that $9.64 \%$ of the observed variance on the respondents' recommendations can be attributed to their perceptions, with the other 90.36\% possibly caused by other factors.

Regression statistics for hypothesis 5 depicts that the relationship between the perceptions on the implementation of attrition system and personnel recommendations to further improve the system is very strong. The coefficient of determination values (R-square) and adjusted coefficient of determination values (Adjusted R-square) indicate the perceptions strongly affect the recommendations respondents.

\section{Table 11}

Analysis of Variance of the perception of the respondents and the recommendations

\begin{tabular}{ccccc}
\hline Source of Variation & SS & MS & $\boldsymbol{F}$ & F crit \\
\hline Regression & 3.248551 & 3.248551 & \multirow{2}{*}{0.70314} & 0.001517 \\
Residual & 27.31623 & 0.303514 & & \\
Total & 30.56478 & & & \\
\hline
\end{tabular}

In terms of variation in regression, the F-computed (10.70314) is much higher than the value of F-critical (0.001517) which indicates that there is a significant difference between the values of perception and recommendations. 
Table 12

Relationships among the Perceptions of the Respondents, Encountered Problems and The Recommendations

\begin{tabular}{cc}
\hline \multicolumn{2}{c}{ Regression Statistics } \\
\hline Multiple R & 0.175566 \\
R Square (Coefficient of determination) & 0.030823 \\
Adjusted R Square & 0.020055 \\
$t$ Stat & 1.691841 \\
$P$-value & $2.29 \mathrm{E}-11 / 0.00$ \\
\hline Hot
\end{tabular}

$\mathrm{H}_{06}$ There are no relationships among the perceptions of the respondents, encountered problems in the implementation of attrition system and their recommendations.

Simultaneous regression analysis was used to examine the joint effects of perceptions and problems on the recommendations of the respondents. This established whether or not the recommendations given are based on valid factors like perception of the system and perceived problems in its implementations. The data on perceptions, problems encountered and recommendations consolidated then subjected to simultaneous regression analyses. This was done to establish whether or not a relationship is existing between and among the main variables in the study: perceptions, problems and recommendations.

Since the $p$-value is much lower than the alpha $(\alpha=0.05)$ or level of significance, there is a relationship $(2.29 \mathrm{E}-11<\alpha)$ among the perceptions of the respondents, problems encountered in the implementation of attrition system and their recommendations. Regression statistics for hypothesis 6 indicate that the perceptions of the respondents and problems encountered in the implementation of attrition system have shaped their recommendations: In straightforward terms, how the respondents perceive the said system regardless of their gender, age, rank/ position and designation within the PNP Maritime Group and problems encountered in the implementation of attrition system have affected their recommendations.

In the perspective of the testing of the strength of the relationship between perceptions and, the coefficient of determination (R-square $=0.030823$ ) reveals that $3.08 \%$ of the changes in recommendations by the respondents can be explained by perceptions and problems in the implementation of the system. Hence, the Null hypothesis is rejected and the alternative hypothesis is accepted. The adjusted coefficient of determination (adjusted $\mathrm{R}$ square) has a value of 0.020055 , indicating that $9.64 \%$ of the observed variance on the respondents' recommendations can be attributed to their perceptions and problems 
encountered in the implementation of attrition system, with the other $97.99 \%$ possibly caused by other factors.

Regression statistics for hypothesis 6 implies that the relationship between the perceptions on the implementation of attrition system, problems encountered, and personnel recommendations to further improve the system is very strong. The coefficient of determination values (R-square) and adjusted coefficient of determination values (Adjusted R-square) indicate the perceptions and problems strongly affect the recommendations respondents.

\section{Table 13}

Analysis of Variance between the perception of the respondents and the recommendations

\begin{tabular}{ccccc}
\hline Source of Variation & $\boldsymbol{S S}$ & $\boldsymbol{M S}$ & $\boldsymbol{F}$ & $\boldsymbol{F}$ crit \\
\hline Regression & 0.942108 & 0.942108 & 2.862325 & 0.094136 \\
Residual & 29.62267 & 0.329141 & & \\
Total & 30.56478 & & & \\
\hline
\end{tabular}

In terms of variation in regression, the F-computed $(2.862325)$ is much higher than the value of F-critical (0.094136) which indicates that there is a significant difference between the values of perception, recommendations. It should be noted that the ANOVA for the sample mean is different from the ANOVA of regression values.

\section{Conclusion}

The respondents perceived that attrition is manifested through attainment of maximum tenure in position, relief from service, demotion in position. Moreover, attrition was carried out because of other reasons like inefficiency, physical and/ or mental incapacity to perform police functions and duties, failure to pass the required entrance examination, twice and/or finish the required career courses, refusal to take a periodic PNP Physical Fitness Test, failure to pass PNP Physical Fitness Test, and non-compliance with the minimum qualification standards for the permanency of original appointment. The employees considered the following as serious problems encountered in the implementation of attrition system: political behavior and organizational politics, the perception that seniority prevail over merit, lack of managerial system or complementary HRM system, personnel with criminal or administrative cases, graft and corrupt practices of some PNP personnel, favoritism, discrimination in terms of commissionship in officer corps, slow and bureaucratic 
recruitment process, failure to satisfy the minimum qualification standards, failure to comply with other requirements for promotion to the next higher rank. Overall, the respondents highly recommended that the PNP Maritime Group establish a rational, fair and transparent placement board, establish promotional system using merits and fitness as the primary consideration ensure equal access and opportunity for professional growth and career advancement for all eligible officers regardless of the source of commission. It is imperative that disciplinary authority act immediately without delay to any protest, complain or grievance arising from the implementation of the circular.

Effective implementation of a policy also requires the implementation of a concrete information and communication management system. For an attrition system to be effective, it is imperative that information about it should be properly disseminated at all levels of the PNP Maritime Group. Moreover, it is imperative that feedback about the current attrition system be collected, processed, and analyzed before creating another policy related to the current system. It is suggested that communication mechanisms like seminars, focus group discussions and conferences pertaining to PNP Maritime Group Attrition System be formulated.

Further research may expand the participants to include higher posts in order to scale the perception and problems encountered during the implementation of the system. Given that this study only focused on the "internal stakeholders" or people who are part of the PNP Maritime Group, it is suggested that a study on the perspectives of the "external stakeholders" or private citizens be solicited on the perception of the police force in general.

\section{References}

Becker, F. (2007). Organizational Ecology and Knowledge Networks. California Management Review, 49(2), 42-61.

Benko, C. and Weisberg, A. (2007). Implementing a Corporate Career Lattice: The Mass Career Customization Model. Strategy \& Leadership, 35(5), 29-36.

Burban Planning, LLP (2021). All You Need to Know About Employee Attrition. https://thebrandboy.com/about-employee-attrition/ 
Crawford, R., Disney, R. and Simpson, P. (2017, January 3). Police officer retention in England and Wales. The Institute for Fiscal Studies. https://ifs.org.uk/publications/8824

Dik, B. (2018). Staff Attrition vs. Staff Turnover: What's the Difference? https://jobzology.com/staff-attrition-vs-staff-turnover-whats-the-difference/

Harsha S., Varaprasad, A., and Sujith, P. (2020). Early Prediction of Employee Attrition. International Journal of Scientific \& Technology Research. Volume 9, Issue 03, March 2020.

Jeen, B.D. (2014). A Study on Attrition - Turnover Intentions in Retail Industry. International Journal of Business and Administration Research Review. Vol.I, Issue No.3, Jan-March 2014.

Knowles, M. (2020, July 23). Police leaving forces in large numbers blaming violence, low pay and social media. https://www.express.co.uk/news/uk/1313375/Police-quittingforces-large-numbers-violence-low-pay-social-media

LinkedIn Corporation. (2018). LinkedIn reveals the latest talent turnover trends: LinkedIn data analysis looks at the industries with the highest turnover rates from 2017. https://news.linkedin.com/2018/3/linkedin-data-analysis-reveals-the-latest-talentturnover-trends?zd_source=hrt\&zd_campaign=5513\&zd_term=chiradeepbasumallick MacIntosh, E. W., and Doherty, A. (2010). The influence of organizational culture on job satisfaction and intention to leave. Sport Management Review, 13(2), 106-117. doi:10.1016/j.smr.2009.04.006

Medina, E. (2012). Job Satisfaction and Employee Turnover Intention: What does Organizational Culture Have to Do with It? https://static1.1.sqspcdn.com/static/f/1528810/23319899/1376576545493/Medina+Eli zabeth.pdf

Norfolk Human Resources Operations (2020). Police Staff Disciplinary Procedure. https://www.suffolk.police.uk/sites/suffolk/files/disciplinary_police_staff_v3_0.pdf

O’Neill, W. (2004). Police Reform and Human Rights: A HURIST Document. New York, Joint Human Rights Strengthening Programme of the United Nations Development Programme and the Office of the High Commissioner for Human Rights (HURIST). 
Philippine Official Gazette (nd). The Philippine National Police (PNP) https://www.officialgazette.gov.ph/featured/about-the-pnp/

Philippine Republic Act No. 6975, Department of the Interior and Local Government Act of 1990. (1990, December 13). https://www.lawphil.net/statutes/repacts/ra1990/ra_6975_1990.html

Reddy, C. (2021). Employee Attrition or Turnover Advantages \& Disadvantages. https://content.wisestep.com/employee-attrition-turnover-advantages-disadvantages/

Robinson, A. (2021, May 16). Employee Attrition: Definition, Causes and Examples. https://teambuilding.com/blog/employee-attrition

Safety Team (2021). 2019's Top Cities for Police Officers. https:/www.safety.com/topcities-police-officers/

Shults, J. (2019). 8 reasons you may need to leave your department. https://www.police1.com/police-jobs-and-careers/articles/8-reasons-you-may-needto-leave-your-department-SwZgD0Uw4f5fCsVo/

Silverthorne, C. (2004). The impact of organizational culture and person-organization fit on organizational commitment and job satisfaction in Taiwan. Leadership \& Organization Development Journal, 25(7), 592-599. doi:10.1108/01437730410561477

Tech Funnel. (2020, May 14). The Ultimate Guide on Employee Attrition. https://www.techfunnel.com/hr-tech/employee-attrition/

The Future of Work 2020. Palo Alto, CA: Institute for the Future, for the University of Phoenix, 2007.http://cdn.theatlantic.com/static/front/docs/sponsored/phoenix/ future_work_skills_2020.pdf

United Nations Office on Drugs and Crime. (UNODC, 2011). Handbook on police accountability, oversight and integrity. Criminal Justice Handbook Series.

Work Institute (2019). 2019 Retention Report: Trends, Reasons, \& A Call to Action. http://info.workinstitute.com/retentionreport2019?zd_source=hrt\&zd_campaign=551 3\&zd_term=chiradeepbasumallick

Zhang, Y.J. (2016) A Review of Employee Turnover Influence Factor and Countermeasure. Journal of Human Resource and Sustainability Studies, 4, 85-91. http://dx.doi.org/10.4236/jhrss.2016.42010 